\title{
A CONTRIBUTION TO THE GENERAL PRINCIPLES OF THE PHARMACODYNAMICS OF SALTS AND DRUGS.*
}

A. P. MATHEWS.

(From the Laboratory of Physiological Chemistry of the University of Chicago.)

Tris paper is a continuation of those already published, ${ }^{\mathrm{x}}$ which have had for their object the investigation of the means by which salts and drugs influence the processes going on in living matter, and thus produce the phenomena of stimulation and depression.

PART I. PHARMACODYNAMIC ACTION DUE TO IONS.

The cause of the pharmacological action of salts upon protoplasm has been the subject of numerous investigations, but until the development of the ionic theory these investigations had led to no further result than to show that in groups of similar metals the heavier were frequently the more poisonous. The application of the ionic theory first brought some order into this part of pharmacology. The work of the American investigators Kahlenberg and True ${ }^{2}$ and Heald, confirmed as it has been by Krönig and Paul, Höber, True, and many others, has shown in the clearest manner that there is a close parallelism between toxicity and the state of ionization of many of the metals, so that these authors conclude that the pharmacological action of any salt solution is a function, in large measure at least, of the ions into which the salt dissociates.

This general conclusion is, in my opinion, as firmly established as is the conclusion that the chemical reactions of such solutions are due to the ions they contain. Indeed, the conclusion is a necessary result of the ionic theory, since the chemical reactions in protoplasm do not differ in nature from those going on elsewhere; and if salts enter into other chemical reactions by their ions, they probably enter also in the same manner into the reactions of protoplasm.

But while this general theory is a great step forward, it stumbles against the objection that many compounds profoundly affect proto-

* Received for publication March 23, 1906.

I MATHEWS, Amer. Jour. Physiol., 1904, I0, p. 29r; 1904, I1, p. 455; 1905, 14, p. 204; 1905, I2, p. 421 ; 1904, II, p. 238.

- Kahlenberg AND TRUE Botanical Gazette, I806, 22, p. 9I. 
plasm, although they do not dissociate electrolytically into ions in the ordinary sense of the term. To explain the action of such compounds as ether and organic drugs, either one must fall back upon the assumption of the action of undissociated molecules, or the idea of dissociation must be extended to cover dissociation which is not accompanied by electrical conductivity. Kahlenberg and True, and indeed nearly all observers, have adopted the theory that some action must be ascribed to undissociated molecules; but it appears to me, in view of the fact that such another kind of dissociation is well known to cccur-as, for example, the dissociation of $\mathrm{NH}_{4} \mathrm{OH}$ into $\mathrm{NH}_{3}$ and $\mathrm{H}_{2} \mathrm{O}$ - and also that this dissociation has been shown by $\mathrm{Nef}^{\mathrm{T}}$ to determine the chemical reactions of such compounds, that the alternative of the action of dissociated particles is the more probable. At any rate, it would be premature to ascribe pharmacological action to undissociated molecules until the possibilities that that action is due to the dissociated particles shall have been proved to be insufficient. In the present paper I shall deal with pharmacological action due to particles dissociated as ions, and in a subsequent paper to action due to non-ionic dissociation. The general principles which I have worked out apply primarily to ionic particles, but I think it altogether probable that they will be found to apply equally well to non-ionic dissociation, since there is in all likelihood no essential difference in kind between such dissociation as that of $\mathrm{NH}_{4} \mathrm{OH}$ into $\mathrm{NH}_{3}$ and $\mathrm{H}_{2} \mathrm{O}$ and ionic dissociation. The two probably differ only in that in the one case the two electrical charges are on the same particle, whereas in ionic dissociation they are on separate atoms. ${ }^{2}$

While, then, it cannot be denied that some action may be referable to undissociated molecules, the clear parallelism between dissociation and pharmacological action in the case of salts, and the equally clear parallelism between non-ionic dissociation and pharmacological action in organic compounds, indicates to my mind that it is to these dissociated particles as the possible cause of pharmacodynamic action that attention should first be directed.

Assuming, therefore, that the action of salts is due in chief measure to the ions of the solution, the first question to be answered is:

NEF, Liebig's Annalen, 1904, 335, p. 192.

- Mathews, Biological Bullelin, 1905, 8, p. 342. See also Nernst, Theoretische Chemie, 4th ed., I903, p. 378 . 
What enables any ion to act at all? What makes a mercury ion, for example, so enormously more toxic than a calcium or magnesium ion? The answer to this question, as I shall now proceed to show, is, that the mercury ion has an enormously greater ionic potential than the calcium ion.

IONIC POTENTIAL AND PHYSIOLOGICAL ACTION.

In an earlier paper ${ }^{\mathrm{I}}$ the term "ionic potential" was suggested to designate the tendency of any ion or atom to change its electrical state. Bodländer has used the term "Haftintensität" to designate the same factor, and he and Abegg have presented evidence to show that the ionic potential is one of the chief factors in determining chemical affinity.

The idea that this property of the ions of the salt might be of importance in determining their physiological action was first suggested by my colleague, Dr. J. Stieglitz, at the meeting of the American Physiological Society in Chicago in December, Igor. At that time the importance and real bearing of the suggestion were not appreciated by me, but about a year or so later I was much struck by the fact that the arrangement of the metals according to their solution tensions, as given by Nernst, was practically the same as an arrangement in the order of their toxic actions. Stieglitz's suggestion appeared to me in a new light, and I set to work to get additional evidence that it is the ionic potential which chiefly determines the physiological action of ions. In I904 I published results showing the remarkable parallelism between toxicity and ionic potential in the action of salts on the eggs of Fundulus heteroclitus. In that paper I showed that valence and ionic velocity-factors to which main importance had been attached by Hardy, Loeb, Pauli, Posternak, and which have been recently emphasized by Robertson ${ }^{2}$-are unimportant when compared with the importance of the ionic potential as a determining factor of toxicity. I showed also that the phenomena of stimulation of the motor nerve by salts demonstrate the same relationship over again, and in the clearest and most decisive manner. Inasmuch as I had already interpreted the phenomena of chemical stimulation of motor nerves to mean that the nerve impulse was due to a progressive coagulation of the colloids of the nerve, it was a

I Mathews, Amer. Jour. Physiol., I904, rr, p. 456.

2 Robertson, Trans. Roy. Soc. of South A ustralia, 1905, 29, p. I I. 
necessary inference, if this were true, that the ionic potential must be of decisive value in determining the precipitation of colloids by electrolytes. An investigation of this possibility showed that this was indeed the case. McGuigan ${ }^{I}$ then investigated the relation between the ionic potential and the power of salts to prevent the action of the diastatic ferment upon starch, and found here also a remarkably close agreement with the theoretical anticipations.

The theory of the importance of the ionic potential has, therefore, been abundantly confirmed. It is the more surprising that it has met with little acceptance or attracted little notice, since its general bearings are exceedingly important, involving as they do the nature of chemical affinity on the one hand, and the basis of pharmacology on the other.

Owing to the importance of the subject, the slight attention it has reccived, and to the fact that my own ideas have become during the course of the work more clear and definite, it seemed to me desirable that the results previously presented both by myself and by others be summarized and put in a more definite, and perhaps a more comprehensible, form, together with new observations in the same direction. Since the solution tension and ionic potential are properties with which physiologists are not generally very familiar, since they lie in another field not hitherto brought into relationship with physiological processes, I have tried to get these ideas clear at the outset.

a) General physical principles involved in chemical stimulation and toxicity.-Any physiological response to an external agent, however that response is produced, implies a change in motion or in state of the atoms, molecules, and masses composing the protoplasmic system. Now such a change in state means that work has been done in producing these movements, and this work must have been done at the expense either of the internal energy of the system itself, or of the energy of the environment-in this case of the substance causing the change. There are accordingly two possible ways in which an external agent such as a salt might produce a change in the protoplasmic system. It may itself supply the energy, in whole or in part, which is necessary to bring to pass the internal movements of the system; or it may by its presence facilitate the transference of the potential

I McGuigan, Amer. Jour. Physiol., 1904, 1o, p. 444. 
energy of the system itself into kinetic. The first method of action is clear, but a word may be said as regards the second. Protoplasm, both in its chemical and physical aspects, shows many of the phenomena of false equilibrium. It is as if there were considerable differences of potential in the protoplasm itself, but these differences were unable to neutralize or equalize themselves, owing to the presence of certain resistances. It is conceivable that our ions may produce results simply by acting as conductors, or in removing resistances; acting, in sther words, as catalytic agents, without specifying more in detail exactly how these act. As an example of this kind of an action I may mention the generation of the nerve impulse when a motor nerve is suddenly immersed in a salt solution, or when its cut and longitudinal surfaces are connected by a wire. In this case the wire or the electrolyte serves by its presence only to equalize the difference in potential between the two surfaces, and the nerve stimulates itself by its own energy. And any electrolyte or any conductor will accomplish this result. To what extent electrolytes may thus affect protoplasmic motions cannot be foretold, but it is certainly possible, and I think on the whole probable, that some of the actions of salts will be found to be of this nature. In such cases the energy content of the salt would be of little importance. But while it cannot be denied that some of the salt action may be of this character, few specific instances are known to me.

In the second place, salts may appear to act catalytically by means of their valence by bringing about combinations between two substances, this combination resulting in one substance hastening the decomposition of the other. The ferments, for example, may in this way be mordanted, as it were, by some bivalent ions to the substances they ferment, in the manner suggested by Henri. ${ }^{x}$ It will, however, be apparent in this case that the power of the ion to form such combinations of the right degree of looseness from which the ferment can again escape, must be dependent on the chemical affinity of the ion. Since the chemical affinity is very probably a function of the ionic potential, this case also really brings us back to the ionic potential as a highly important factor in the ion's action.

We may now turn from these hypothetical cases to the other possi-

I HeNRI, Revue générale des sciences, 1905, 16th year, p. $64 \mathrm{I}$. 
bility in which salts affect the protoplasmic movements in virtue of their own energy content.

In this case also the action of the salt may be twofold. It may either change the whole protoplasmic system by means of the energy in the salt, or it may by a transfer of a portion of its energy to one part of the protoplasm produce such a change in the latter that energy is set free by the protoplasm itself. It is clear, in other words, that the salt may destroy the protoplasm either directly, in virtue of a great interchange of energy between itself and the protoplasm, or it may destroy it indirectly, by acting on some part of the protoplasm in such a way that its own energy destroys it, or that the normal conversion of potential into kinetic energy necessary for the continuance of the vital processes is checked.

A distinction is generally made between these two forms of destruction, in that substances acting in the first manner are said to be immediately fatal; those acting in the second manner are said to exhaust the protoplasm by over-stimulation or depression. Thus mercuric chloride in large doses probably produces an immediate coagulation and destruction of the living matter. In this case an immediate and complete change in the protoplasmic system would be produced by the transfer of energy from the salt to the protoplasm as a whole. On the other hand, mercuric chloride may destroy living matter in small doses, not by this method, but by bringing about a small change in the protoplasm, by means of which internal resistance of some kind is withdrawn or increased, and the protoplasm destroys itself. In both these cases, however, the destruction of the protoplasm is a direct result of the energy content of the salt, and salts will be poisonous according as the amount of free energy in them is great or small.

For all salts and compounds producing changes in the protoplasmic system in the two last ways the chemical composition will be of little or no importance; the sole or most important factor determining action will be the potential and amount of the energy in it. The character of the carrier of the energy, in other words, is immaterial.

The foregoing considerations may be expressed in a formula:

Poisonous action of any salt $=$ work done by it $=$ avail able energy in it=amount of energy $\times$ its potential. 
In the action of salts on protoplasm we have to deal, then, with a transfer of energy from the ions to the protoplasm, or vice versa. From the general principles of physics we conclude that the physiological action of any salt solution must be a function of its energy content. The question arises how this energy content is to be measured.

It has been shown that much, if not all, of the action of salt solutions is due to the ions present. We must, therefore, measure the energy content of the ions. The total energy of the ion is composed of two factors, the free or available energy and the bound energy. It is only the free energy, or that which can be transferred to or from the ion, which is of importance in this connection.

I. The potential factor of the free energy.-The interchange of energy between the salt solution and the protoplasm must depend on the relative potentials of the two systems, since whether any substance can transfer energy to another depends, not on the total amount of energy in the two substances or systems, but on the potential of the energy in the two cases. The action of any salt solution is then determined by its available energy, and by the available energy in any salt is meant the product of the difference of potential between the protoplasm and the salt multiplied into the amount of energy transferred from one to the other before the potential is equalized. If the protoplasm and the ion have energy at the same potential, the difference in potential will be zero, the available energy is hence zero, the work done is zero, and the ion should produce no direct effect due to its energy content on protoplasm, though it might affect it catalytically in the manner indicated.

2. Total free energy.-The total free or available energy of any ion is composed of two factors, the potential energy and the kinetic energy. The kinetic energy, or energy of motion, will be equal to $\frac{1}{2} M V^{2}$. As I do not know the actual velocity of ionic movement when the potential gradient is unknown, I am unable to determine the kinetic energy. It is, in any case, generally small when compared to the potential energy, although not negligible when the latter factor approaches zcro. That is, if the potential of two ions and the protoplasm are about the same, these ions may have different actions owing to differences in their kinetic energy, i. e., their ionic masses and velocities. In this paper, however, I shall consider only the potential energy factor. 
3. The potential energy of ions.-What is the measure of the potential energy of any ion? The potential energy must be the difference in the energy content of the ion or atom in different conditions. If any substance has any available potential energy, it necessarily means that it is capable of existing in two conditions which differ in their energy content, and that it gives up energy in passing from one con. dition to the other. That ions and atoms do exist in such different conditions is well known. Thus the chemical differences between atomic and ionic sodium, and between ferric, ferrous, and metallic iron, are due to differences in the energy content of the atoms in different conditions. The available potential energy of the sodium atom is very much greater than that of the sodium ion, as is indicated by the fact that when the atom becomes an ion, a large amount of heat is set free.

The potential energy of the ion must be sharply distinguished from the ionic potential. The potential energy is in its turn composed of a capacity and an intensity factor; the capacity factor being represented by the amount of electricity transferred; the intensity factor, by the tendency of the ion or atom to change its state; in other words, by its stability or ionic potential. The potential energy of any ion must be measured hence by the ionic potential multiplied into the capacity. The capacity factor falls out of account if equivalent solutions are compared, since in that case each equivalent has the same quantity of electricity in it, and the differences between the actions of ions are hence due to differences in ionic potential. The question now comes down to the determination of the ionic potential.

4. The determination of the ionic potential.-In my earlier papers it was not clear to me how this ionic potential could be determined, so I used instead, as a rough measure of it, the solution tension of the metal. I assumed that the solution tension would be the reciprocal of the ionic potential. Inasmuch as the solution tension varies with the concentration of the salt, I used arbitrarily the solution tension of the metals in normal ionic solution.

Inasmuch as the determination of the ionic potential depends on the determination of the solution tension, it is necessary to understand the latter term, and as this may not be familiar to all physiologists, the following explanation is given: 
TABLE I.

\begin{tabular}{|c|c|c|c|}
\hline \multicolumn{3}{|c|}{ Cations } & Anions \\
\hline K & $-2.9^{2}$ & -0.493 & -1.604 \\
\hline $\mathrm{Na}$ & $-2 \cdot 54$ & $\mathrm{Cd} \quad-0 . \mathrm{I}_{43}$ & $-1.27^{\circ}$ \\
\hline $\mathrm{Ba}$ & $-2 \cdot 54$ & $\mathrm{Fe}^{\prime \prime}-0.063$ & I $\quad-0.797$ \\
\hline $\mathrm{Ca}$ & -2.28 & Co +0.045 & $\mathrm{NO}_{3}-2.229$ \\
\hline a & - - . $88(?)$ & +0.049 & \\
\hline $\mathrm{Sr}$ & $-2.49(?)$ & +0.129 & \\
\hline $\mathrm{Li}$ & $-2 \cdot 3^{2}$ & $\mathrm{H}+0.277$ & \\
\hline $\mathrm{Mg}$ & -2.26 & $\mathrm{Fe}^{\prime \prime \prime}+0.3^{\mathrm{I}} 4(?)$ & \\
\hline & $-1.48(?)$ & $\mathrm{Cu}+0.606$ & \\
\hline & -0.999 & +1.027 & \\
\hline M & -0.798 & +1.048 & \\
\hline
\end{tabular}

When a plate of metal is placed in water, a certain amount of the metal passes into the water in the form of positively charged particles, so that the solution becomes positively charged, the metal negatively charged. The tendency of different metals to throw off these positive particles varies, and this tendency may be measured in so many volts if the metal is placed in a solution of one of its salts of known strength. If this is done and the difference in voltage between the metal and solution is measured, one obtains a series of values for the different metals, and these values are known as the solution tension series of the metals. The measurements are generally referred to the metals when immersed in normal ionic solutions of their salts (Table r).

By a reference to Table I showing this series it will be found that potassium and sodium stand at one end of the series, these metals having in normal ionic solutions a negative voltage of 2.92 and 2.54 respectively, as compared with the solution; while at the other end are the noble metals, gold, silver, platinum, and mercury, which immersed in normal ionic solutions become electropositive to the extent of more than one volt.

The solution tension measures therefore the difference in potential between the solution which contains a known quantity of the ions of the metal and the metal itself; and it expresses the difference between the tendency of the ion to deposit itself on the metal plate, and the tendency of an atom of the plate to become an ion. It will be seen that the values of the solution tension depend entirely on the concentration of the ions in the solution, and the presence of a plate or particle of the metal. For our purposes, therefore, 
it is clear that the ordinary figures given for the solution tension are not strictly applicable to the physiological conditions. We introduce into the salt solution, not a plate of metal, but a particle of protoplasm, and we wish to know what is the tendency of any ion in that solution to give up its charge in whole or in part to the protoplasm. The solution tension is not therefore a proper measure of the particular property of the ion we seek.

In previous work, in order to get comparable results, I had to adopt arbitrarily the solution tension of the metals in the normal ionic solutions of their salts, although there was no reason at all why this value, rather than the value in any other concentration, should have been taken.

It is clear that what is most important in the ion in determining its physiological action, and its chemical action as well, is not the difference of voltage between a plate of metal and any solution of its salts, but rather the difference in pressure between a single ion and a single atom of the metal. That is, it is the inherent tendency of any ion in any concentration to change into an atom of its metal. This last property has been called the ionic potential. The method of computing it is as follows:

Nernst ${ }^{1}$ has shown that the formula which expresses the amount of work necessary to compress a gas from volume I to volume 2 is of very general applicability, and also expresses the amount of work necessary to transform one gram atom of a metal into one gram ion at any concentration. This formula is as follows:

$$
\text { Amount of work }=L=R T \ln \frac{v_{\mathrm{I}}}{v_{2}} \text {. }
$$

In this formula $R$ is the gas constant; $T$, the absolute temperature; $v_{\mathrm{x}}$ and $v_{2}$ the gas volumes; and the logarithm is the natural logarithm. This formula may also be expressed using pressures instead of volumes, or:

$$
L=R T \ln \frac{p_{2}}{p_{\mathbf{r}}}
$$

In this formula $p_{1}$ is what is known as the solution pressure of the metal, and $p_{2}$ the osmotic pressure of the ions of the metal in the solution. Instead of $p_{\mathrm{x}}$ we may write $P$. By taking $R$ and $T$ in absolute

I Nernst, Theoretische Chemie, 1903, 4te Aufl. 
units, and remembering that in all cases one gram ion carries $n \times 96,540$ coulombs of electricity, where $n$ is the valence, this formula may be expressed in the form of potential in volts existing between the metal and solution, ${ }^{\mathrm{I}}$ i. e.:

$$
E=\frac{R T}{n} \ln \frac{p_{2}}{P}=\frac{0.057}{n} \log _{\mathrm{To}} \frac{p_{2}}{P} \text { volts. }
$$

If this potential is measured directly by connecting the metal immersed in a solution of its salt through a voltmeter with an electrode of known potential, $E$ may be measured, and then $P$ is easily calculated. When $P$ is once known, $E$ may be calculated when the metal is immersed in any solution of its salts of which $p_{2}$ is known.

To determine the real ionic potential from this formula, one proceeds as follows: It is obvious that the formula expresses the amount of work done in accomplishing two different things. It expresses the sum of the work necessary to transform one gram atom of metal into one gram ion in the same space, plus the amount of work (negative) necessary to expand the one gram ion from this space to one liter or the space it finally occupies. It is the first of these factors which we wish to determine, since this measures the ionic potential. The formula may accordingly be written as follows:

$$
L=R T \ln \frac{p_{2}}{P}+R T \ln \frac{p_{3}}{p_{2}}
$$

In this formula $p_{2}$ is the osmotic pressure of the positive ions of the metal when at the same concentration as the atoms of the metal; and $p_{3}$ is the osmotic pressure of the ions when at the concentration of one gram ion to the liter. Accordingly, the first term of the right-hand member of the equation measures the work necessary to transform one gram atom of the metal into one gram ion occupying the same space, and the second term measures the work done (negative) in expanding from this space to one liter. Expressing this formula in volts, and putting $C=$ concentration in place of $p$, and passing to common logarithms

$$
E=\frac{0.057}{n} \log \frac{c_{2}}{C}+\frac{0.057}{n} \log \frac{c_{3}}{c_{2}} .
$$

In this equation $E$ is determined by measurement, and the sccond term is easily calculated. The middle term, or the ionic potential, is then 
obtained by the difference between $E$ and the second term. For example, a silver plate in contact with a normal ionic silver nitrate solution shows a difference of potential between itself and the solution of $+\mathbf{I} .048$ volts. $\therefore E=+\mathrm{I} .048$ volts. $c_{2}$ is the concentration of silver atoms in metallic silver. One gram atom of silver-i. e., 107.9 TABLE 2.

The Ionic Potentials of the Ions of Metals in Volts.

$\begin{array}{lll}\mathrm{K}-2.92(?) & \mathrm{Cd}-0.089 & \mathrm{O}-0.426 \\ \mathrm{Na}-2.54(?) & \mathrm{Fe}^{\prime \prime}+0.00 & \mathrm{Cl}-\mathrm{1} .694(?) \\ \mathrm{Li}-2.32(?) & \mathrm{Co}+0.107 & \mathrm{Br}-1.270(?) \\ \mathrm{Ba}-2.54(?) & \mathrm{Ni}+0.112 & \mathrm{I}-0.797(?) \\ \mathrm{Ca}-2.26(?) & \mathrm{Pb}+0.179 & \\ \mathrm{Sr}-2 .(?) & \mathrm{H}+0.107(?) & \\ \mathrm{Mg}-\mathrm{I} .160 & \mathrm{Cu}+0.668 & \\ \mathrm{Mn}-0.737 & \mathrm{Hg}+\mathrm{1} .080 & \\ \mathrm{Zn}-0.434 & \mathrm{Ag}+\mathrm{I} .163 & \end{array}$

grams of silver-occupies the space at $18^{\circ}$ of Io. I c.c.; i. e., the atomic weight in grams divided by the specific gravity. $c_{2}$, or the number of gram atoms of silver in one liter of silver, $=\frac{\mathrm{IO00}}{\mathrm{IO} . \mathrm{I}} \cdot c_{3}$ $=\mathrm{r}$, since the concentration of silver ions is one gram ion per liter. Substituting these values in (I),

or

$$
\text { I } .048 \text { volts }=0.057 \log \frac{c_{2}}{C}+0.057 \log \frac{10 . \mathrm{I}}{1000}
$$

$$
\text { I. } 163=0.057 \log \frac{c_{2}}{C} \text {. }
$$

There is hence a difference of potential of $I .16_{3}$ volts between one atom of silver and one ion, in favor of the ion. That is, when one gram ion of silver changes into one gram atom in the same space $96,540 \times 1$. 163 Joules of energy are set free, or since each monovalent ion carries $9.65 \times 10^{-20}$ coulombs of electricity, when one silver ion changes into a silver atom at any concentration, $9.65 \times 10^{-20} \times 1.163$ Joules of energy are set free.

It will be seen, by comparing Tables $\mathrm{I}$ and 2 , that the true values of the ionic potential calculated in this way do not in most instances differ greatly from the values of the solution tension in normal ionic solutions. The heavy metals have, as a rule, an ionic potential about $0.07-0.1$ volts different from the solution tension in normal ionic solutions.*

* I have not calculated the ionic potentials of $\mathrm{Cl} \mathrm{Br}$, and I, but have used instead the figures for solution tension in normal ionic solution. It is also impossible to calculate the ionic potentials of $\mathrm{Ca}, \mathrm{Li}, \mathrm{Ba}$, $\mathrm{Na}$, and $\mathrm{K}$. 
A word may be said about the reliability of these figures. They depend, as will be seen, upon direct measurements of the electromotive force shown between two metals when immersed in known solutions of their salts, those solutions being in contact. This assumes a knowledge of the number of ions of metal in the salt solutions in question, and this factor is not in all cases perfectly certain. A much more serious source of possible error arises from a determination of the potential of any single metal, since it is necessary to know the potential of at least one electrode before the rest can be determined. The measurement is ordinarily made by using the calomel mercury electrode, which is supposed to have a potential of +0.56 volts. This voltage was determined by measuring the potential between a dropping mercury electrode, which theoretically should have a zero potential, and the calomel mercury electrode. Recent determinations of the potential of the calomel mercury electrode by a totally different method by Billitzer ${ }^{\mathrm{x}}$ give a different value. It is, therefore, impossible at present to say which of these measurements or methods gives the more reliable result. Nernst has accordingly proposed that the hydrogen electrode in normal ionic solution be regarded arbitrarily as zero, until the absolute potential is determined. I have, however, used the values as given by Wilsmore, based on the calomel electrode 0.56 .

The question does not influence most of the measurements which follow, since these are based on the sum of the potentials of both anion and cation, or upon the differences between two like ions. This is a constant whatever the absolute potential, since if a certain number is added to the anion, it will be subtracted from the cation. For example, suppose it be shown by a change in the point of zero potential that the solution tension of sodium is 2.34 instead of 2.54 , this increases the ionic potential by 0.2 volt; but if sodium is 2.34 , then chlorine is 1.894 instead of $x .694$, and this reduces the ionic potential of chlorine by 0.2 volt. The sum of the potentials of sodium and chlorine remain unchanged.

b) The relation between physiological action and ionic potential.To bring out the relationship between ionic potential and toxic action, I have prepared Table 3, which shows this relationship for the toxic

'BILLITZER, Zischr. für Eleklrochemie, 1902, 8, p. 638. 
action of salts on fish eggs, ${ }^{1}$ the diastatic ferment, ${ }^{2}$ bromelin, ${ }^{3}$ a proteolytic ferment, and growing tips of peas and beans. ${ }^{4}$ Table 3 shows that the chlorides of the various metals arrange themselves, as regards their toxicity, with few exceptions, in the order of the potential energy of their ions. Ions of low potential energy, such as those of sodium, lithium, magnesium, and potassium, being relatively inert, when compared with the enormously toxic action of the ions of high potential energy, such as nickel, lead, hydrogen, ferric, cupric, mercury, silver, gold, and platinum.

There is, I think, no mistaking this general parallelism, which was theoretically anticipated. By no other properties known to us can the metals be arranged in an order so closely corresponding to their

TABLE 3 .

Minimum Fatal. Doses of Salts for Various Ferments and Organisms.

$(\boldsymbol{V}=$ Dilution Minimum Fatal Dose (Equivalent).)

\begin{tabular}{|c|c|c|c|c|c|c|c|}
\hline \multirow[b]{2}{*}{ SALT } & \multicolumn{7}{|c|}{ Mrntmum Fatal Dose ( $V$ ) Equrvalent Drution } \\
\hline & Diastase & $\begin{array}{l}\text { Eggs of } \\
\text { Fundulus }\end{array}$ & $\begin{array}{c}\text { Cilia } \\
\text { Volvox }\end{array}$ & Bromelin & $\begin{array}{l}\text { Roots of } \\
\text { Pisum }\end{array}$ & $\begin{array}{l}\text { Roots of } \\
\text { Zea mais }\end{array}$ & $\begin{array}{l}\text { Roots of } \\
\text { Lupinus }\end{array}$ \\
\hline $\mathrm{Ag} \mathrm{NO}$. & $<100,000$ & 100,000 & 300,200 & I $10, \infty 00$ & 204,800 & 300,000 & 300,000 \\
\hline $\mathrm{Hg} \mathrm{NO} \mathrm{Ng}_{4} \cdot$ & & & $\ldots \ldots$ & 75,000 & & & $\ldots \ldots$ \\
\hline $\begin{array}{l}\mathrm{Hg} \mathrm{Cl} \\
\mathrm{Hg}(\mathrm{CN})_{2} \ldots \ldots \cdots\end{array}$ & $\begin{array}{l}30,000 \\
\ldots \ldots\end{array}$ & 50,000 & $\cdots \cdots$ & $\cdots \cdots$ & 204,800 & 25,600 & $\ldots \ldots$ \\
\hline $\begin{array}{l}\mathrm{Hg}(\mathrm{CN})_{2} \\
\mathrm{Cu} \mathrm{SO}\end{array}$ & $\cdots$ & $\cdots \cdots$ & $\cdots \cdots$ & 30,000 & $\begin{array}{ll}\cdots \\
5 \mathrm{I}, 200\end{array}$ & $\dddot{102,4 \infty}$ & $\begin{array}{l}51,200 \\
12,800\end{array}$ \\
\hline $\mathrm{Cu} \mathrm{Cl}_{2}$. & 8,333 & 15,000 & $\ldots \ldots$ & 24,000 & $5 I, 200$ & 102,400 & I 2,800 \\
\hline $\mathrm{Te} \mathrm{Cl}_{3} \ldots$ & $333(?)$ & 4,000 & $\cdots \cdots$ & $\ldots \ldots$ & $\cdots \cdots$ & $\cdots \cdots$ & $\because \ldots$ \\
\hline $\begin{array}{l}\mathrm{Pb}\left(\mathrm{NO}_{3}\right), \ldots \ldots \\
\mathrm{Pb} \mathrm{Cl}_{2} \ldots \ldots \ldots\end{array}$ & $\begin{array}{ll}30(r) \\
\ldots \ldots\end{array}$ & $\begin{array}{l}\cdots, 000 \\
5,00\end{array}$ & $\cdots \cdots$ & $\begin{array}{l}20,000 \\
18,500\end{array}$ & $\cdots \cdots$ & $\begin{array}{ll}\ldots \ldots \\
\ldots \ldots\end{array}$ & $\begin{array}{l}0,700 \\
\ldots \ldots\end{array}$ \\
\hline $\mathrm{Pb}\left(\mathrm{C}_{2} \mathrm{H}_{3} \mathrm{O}_{2}\right)_{2} \ldots$ & $\cdots \cdots$ & 5,000 & $\cdots \cdots$ & 10,500 & & ?....... & an.... \\
\hline $\mathrm{HCl} \ldots \ldots \ldots$ & 990 & 3,000 & $\ldots \ldots$ & $\ldots \ldots$ & 12,800 & 3,200 & 3,200 \\
\hline $\mathrm{Cd}\left(\mathrm{NO}_{3}\right)_{2}, \ldots \ldots$ & $\cdots \cdots$ & I2,500 & $\ldots \ldots$ & 3,000 & $\cdots \cdots$ & …... & 51,200 \\
\hline $\begin{array}{l}\mathrm{Cd}_{\mathrm{Ni}}^{\mathrm{Cl}_{2}}, \ldots \ldots \ldots \ldots \ldots \\
\end{array}$ & $\begin{array}{l}142 \\
910\end{array}$ & $\begin{array}{r}12,500 \\
500\end{array}$ & $\begin{array}{c}500 \\
\ldots \ldots\end{array}$ & $\ldots \cdots$ & …... & …... & ….... \\
\hline $\mathrm{Ni} \mathrm{SO}$ & & & $\ldots \ldots$ & $\ldots \ldots$ & $\dddot{51,200}$ & 51,200 & 12,800 \\
\hline $\mathrm{Co} \mathrm{Cl}_{2} \ldots$ & 100 & 250 & $\cdots \cdots$ & & $\ldots \ldots$ & 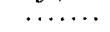 & \\
\hline $\mathrm{Co} \mathrm{SO}_{4} \ldots \ldots \ldots$ & $\ldots \ldots$ & $\cdots \cdots$ & $\cdots \cdots$ & 2,250 & $\ldots \ldots \ldots$ & $\cdots \ldots$ & 12,800 \\
\hline $\begin{array}{l}\mathrm{Co}\left(\mathrm{NO}_{3}\right)_{2} \ldots \ldots \ldots \\
\mathrm{Fe}\left(\mathrm{Cl}_{3} \ldots \ldots \ldots \ldots\right.\end{array}$ & $\cdots \cdots$ & $\begin{array}{r}\cdots \\
\text { IO }\end{array}$ & $\ldots \ldots$ & 2,400 & $\ldots \ldots$ & $\ldots, 400$ & \\
\hline Fe SO ${ }_{4} \ldots \ldots \ldots$ & $\ldots \ldots$ & & $\cdots \cdots$ & $\ldots \ldots$ & $\ldots \ldots$ & & 6,400 \\
\hline $\mathrm{Zn} \mathrm{Cl} \ldots$ & 69 & 800 & …. & $\ldots \ldots$ & …... & ….. & …... \\
\hline $\mathrm{Zn}\left(\mathrm{SO}_{4} \ldots\right.$ & $\cdots \cdots$ & a..... & …... & $8,35^{\circ}$ & …..... & ….... & a........ \\
\hline $\mathrm{Mn} \mathrm{Cl}_{2}$. & 6.25 & 4 & I5 & $\ldots \ldots$ & …..: & $\cdots \cdots$ & $\ldots \ldots$ \\
\hline $\mathrm{Al} \mathrm{Cl}_{3} \ldots \ldots \ldots \ldots$ & $3 \cdot 3$ & $\begin{array}{l}3 \\
2\end{array}$ & $\cdots \cdots$ & $\ldots \ldots$ & $\cdots \cdots$ & …? & …... \\
\hline $\mathrm{Mg}\left(\mathrm{NO}_{3}\right)_{2} \ldots \ldots$ & $\ldots \ldots$ & & & 325 & …..... & ……. & ......... \\
\hline Li Cl........... & $x .4$ & 4 & $\cdots \cdots$ & $\begin{array}{r}\text { I, }, \infty \circ \\
\text { (Licl) }\end{array}$ & …... & ….... & ….... \\
\hline $\mathrm{Ca} \mathrm{Cl}_{2}$. & 4 & $3 \cdot 5$ & 5 & $\cdots \cdots$ & $\ldots \ldots \ldots$ & $\ldots \ldots \ldots$ & $\ldots \ldots \ldots$ \\
\hline $\mathrm{BaCl}_{2}$. & I. I & 2 & & $\ldots \ldots$ & $\ldots \ldots$ & $\ldots \ldots$ & $\ldots \ldots$ \\
\hline $\mathrm{Li} \mathrm{Cl}_{2} \ldots \ldots \ldots \ldots$ & 2.5 & I. 5 & ...... & 400 & …... & $\cdots \cdots$ & …... \\
\hline$\underset{K}{\mathrm{Na}} \mathrm{Cl} . \ldots \ldots \ldots$ & $\begin{array}{l}>3 \\
>3\end{array}$ & 2 & $\cdots \cdot \cdots(?)$ & ...... & $\cdots \cdots$ & $\cdots \cdots \cdot$ & $\cdots \cdots$ \\
\hline $\mathrm{Na} \mathrm{NO}_{3} \ldots \ldots \ldots \ldots$ & $\ldots \ldots \cdot 3$ & $1 \cdot 3$ & $\ldots . .$. & $1,600(?)$ & ….... & ….... & …..... \\
\hline $\mathrm{K} \mathrm{NO}_{3} \ldots \ldots \ldots \ldots$ & $\ldots \ldots$ & $\ldots \ldots$ & $\ldots \ldots$ & 100 & ....... & $\ldots \ldots$ & $\ldots \ldots$ \\
\hline
\end{tabular}


toxic action. For example, suppose it was attempted to classify them in the order of their ionic weights. It will be seen that no parallelism exists between toxic action and ionic weight, since we have nickel, atomic weight 58 , lead, atomic weight 200 , hydrogen, atomic weight $\mathrm{I}$, and copper atomic weight 32 , following each other closely. Furthermore, attention may be called to the enormous difference in toxicity, existing between the same atom when carrying two different quantities of potential energy. Ferrous iron has as an ion very little potential energy compared with ferric iron, and it is enormously less poisonous than the latter.

It will be noticed also that in each of these cases certain metals come out of their proper order of toxicity and potential. In the case of Fundulus eggs, cadmium is considerably out of its proper place, whereas it follows the rule in the case of diastase; for diastase, lead is quite out of its position; for bromelin, the great exception is barium, which is very toxic. The causes of these special and sporadic exceptions will be taken up later.

TABLE 4.

Minimum fatal Dose and Iontc Potential of Anions.

(Eggs of Fundulus heteroclitus.)

\begin{tabular}{|c|c|c|}
\hline Salt & V (Min. Fatal Dose) & Anionic Potential \\
\hline 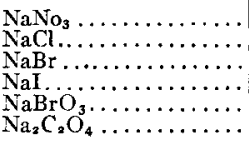 & $\begin{array}{r}2.0 \\
2.0 \\
2.7 \\
4.0 \\
11.0 \\
35.0\end{array}$ & $\begin{array}{l}-2.229(?) \\
-1.694 ، \\
-1.2700 \\
-0.797 ، \\
-0.727 ، \\
-0.109\end{array}$ \\
\hline
\end{tabular}

If now we turn to the negative ions, or anions, a similar parallelism is shown to exist between toxicity and potential energy content. Thus chlorine is in all cases far less toxic than iodine, which has twice as much potential energy. The oxalates and cyanides and sulphites are the more toxic, the greater their available energy content. Unfortunately, our knowledge of the potentials of the anions is less exact than our knowledge of the potentials of the cations, so that it is impossible to follow the correspondence in detail; but sufficient is shown to prove that the same correspondence between toxicity and potential energy exists here as in the cations.

c) The quantitative relationship between ionic potential and the minimum fatal dose.-It was shown at the outset that the amount of 
work any ion can do must depend upon its available potential energy; i. e., upon the product of the difference of potential between the protoplasm and the ion multiplied into the quantity of energy transferred before the potentials were equalized. Of two positive ions holding different quantities of available potential energy, that which has the more energy can do the more work. The total amount of work any number of positive ions can do will depend on the concentration of the the ions and amount of available potential energy in each ion. If we take as a standard a certain amount of work-let us

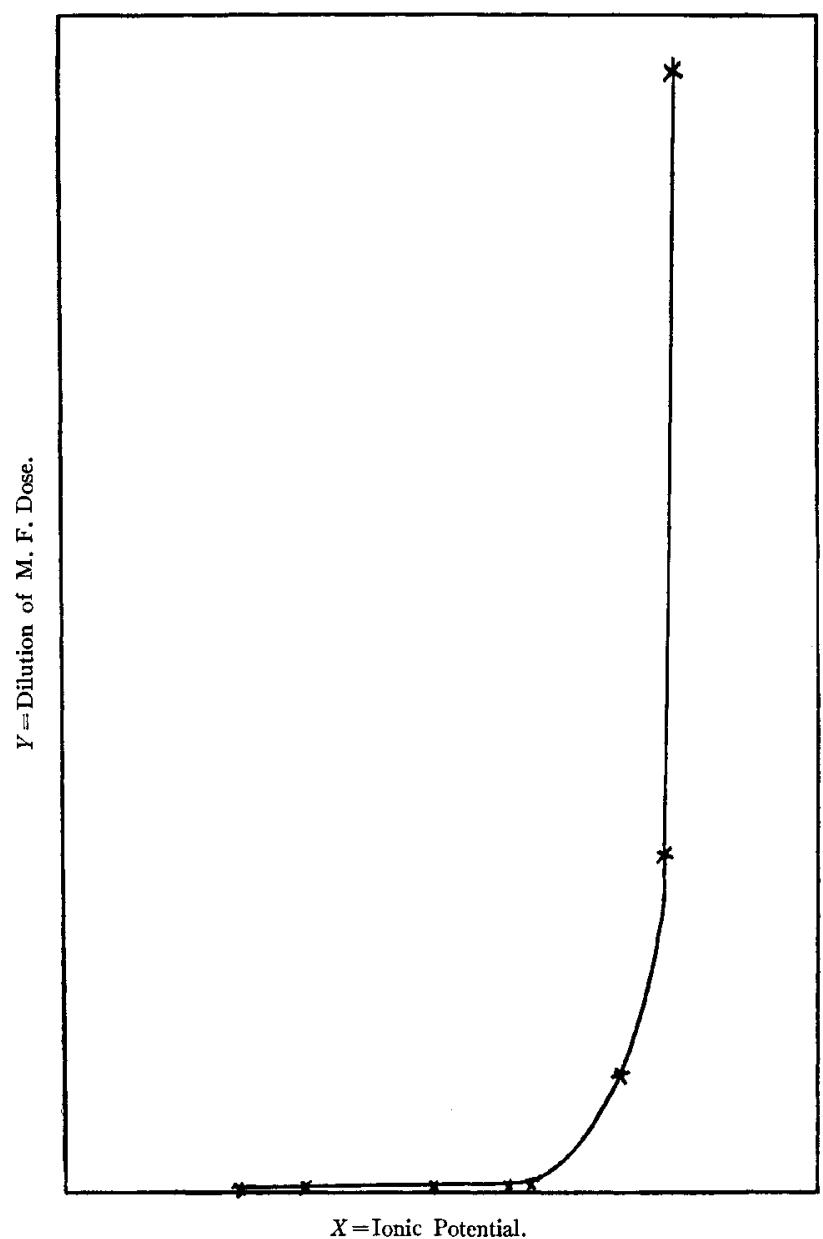

Fig. I. Ordinates represent the dilution of the minimum fatal dose Abscissæ represent the cation potential. 
say the amount of work just sufficient to kill protoplasm in unit time, say 24 hours-the concentrations of the two ions which will just accomplish this work must stand in some numerical relation to their potential energy content. What is that relation?

To bring out this relationship, I have plotted the curve in Fig. I, which expresses the relationship between the ionic potential of the cation and the dilution $(V)$ of the minimum fatal dose. By dilution is meant the number of liters of solution containing one gram equivalent of the salt. From an inspection of this curve it will be seen that we are dealing with a logarithmic function; that is, the dilution increases enormously in a logarithmic ratio to the ionic potential. The dilution, for example, increases roo,ooo times while the ionic potential increases about five times.

By inspection of this curve one may write the general equation:

$$
\log _{10} V=K E \text {. }
$$

In this formula $E$ is the ionic potential, $V$ the dilution, and $K$ the constant of proportion. If, however, we place $\frac{\log V}{E}=K$, it will be seen that this formula is not in the right form, since $E$ for some ions is zero. Nor does the formula $\log V=\frac{K}{E_{\alpha}+E_{c}}$ give constant results. In this formula $E^{c}+E^{a}$ represents the sum of the potentials of the anion and cation. Nor could it be anticipated that such a formula would give a proper result, since what we have to express is the difference of potential between the salt and the protoplasm, and this formula expresses only the relation between minimum fatal dose and the absolute potential of the various ions. Before setting up any theoretical formula, it is necessary to get clearly in mind just in what the difference in potential between the protoplasm and the salt consists.

d) Derivation of a theoretical formula expressing the relationship between minimum fatal dose and the available potential energy of salt solutions.-We have now found out how to measure the potential of the potential energy of the salt solution; it is necessary that we discover also how the potential of the potential energy of the protoplasmic system is to be determined, since our formula involves both these factors, the available potential energy being the difference between the potentials of the salt and the protoplasm. 
The protoplasmic system is made up of masses of proteid matter in equilibrium apparently with particles of the same proteid in solution. It may be regarded as a two-phase colloidal system. We may assume, in the light of the investigations of the past five years, that changes in the protoplasmic activity are due, in part at least, to changes in the state of these colloidal particles and masses, and that the salts are affecting vital processes in part by producing such changes. What we have to compare, then, in the first instance, is the potential of the energy of the protoplasmic colloids with the potential of the potential energy of the ions of the salt solution. We have, therefore, to get a clear idea of the relationship of salts to the precipitation and solution of colloids.

Since the protoplasmic colloids are for the most part composed of albumin in combination with other radicles, it is to the albuminous or proteid colloids to which attention may first be directed. The work of Kossel and Fischer has cleared up the structure of the albumin molecule, which has been shown to be a polymer of amino acids. As a result, albumin or proteid is shown to be both acid and basic; that is, it is capable of uniting with metals to form true salts, and also with acids through the amino group.

If common egg albumin is dissolved in alkaline solution, it exists as sodium albuminate; if it is dissolved in hydrochloric acid, it exists as albumin chloride. Sodium albuminate dissociates electrolytically, owing to the high dissociating power of sodium (that is, its high solution tension), and $\mathrm{Na}+$ and albumin ions are formed. Similarly, owing to the high dissociating power of the chlorine, albumin chloride dissociates into albumin and $\overline{\mathrm{Cl}}$ ions. This dissociation results in giving the albumin - that is, the colloidal particle-a positive or negative electric charge. It is possible to change the sign of the charge on the albumin particles by making an alkaline solution sufficiently acid. This is brought about in the following way: By adding acid to the alkaline albumin the highly dissociated sodium compound is replaced by the slightly dissociated hydrogen compound. The result of this is that the charge on the colloid is neutralized, undissociated albumin is formed, and if the concentration of the albumin is sufficiently great, precipitation will occur. If one continues to add 
acid, the albumin combines with the hydrochloric acid and goes over into the chloride. This at once dissociates the chlorine ion as a negative ion, and the albumin becomes the cation. It will, however, be clear that, although in this case the albumin is mainly electropositive, yet it is an acid, and the ionization of its hydrogen is not completely suppressed, although it is reduced to a very small amount. This means that here and there are albumin particles which are at one spot electronegative, since they dissociate hydrogen, and in another spot electropositive, since they dissociate chlorine. We have some amphoter or twin ion colloids, in other words. The evidence of the existence of such ions will be taken up on p. ro4.

I make this explanation at such length because it does not appear to be clear to many that the albumin colloids owe their charges to processes of ionization, just as any salts owe their charges to these processes. Thus several writers have assumed that the charge was owing to the salt introduced. The ion of the salt introduced which moved fastest was supposed to bury itself in the colloid particle, and thus give its charge to it. This hypothesis is quite unfounded and undoubtedly erroneous.

The proteids, therefore, in protoplasm exist as salts, and dissociate sodium or other metallic ions, and chlorine and other anions, and the colloids thus become charged. Some proteids here and there dissociate both positive and negative ions. The colloids in protoplasm are undoubtedly in the condition of a saturated solution, and we have an equilibrium between dissociated and undissociated colloids, in solution, and undissociated and dissociated precipitated colloids.* It has been shown, furthermore, that the state of solution and the fineness of subdivision of the colloidal particles depend on the number of free electrical charges on their surfaces. The greater the number of similar charges, the greater the solubility of the colloid.

In determining the potential of the potential energy of the colloid, we have, then, just the same factors to consider as in the salts, since the colloids are salts. The potential of the energy content of the colloid solution must be determined by the ionic potentials of the ions into which it dissociates, for example, the potentials of sodium and albumin.

\footnotetext{
*As a possible example of a dissociated insoluble colloid, fibrin which has been in acid may be mentioned. This fibrin dissociates hydrogen, but the hydrogen ion is unable to move away from the fibrin. The condition is very similar to the double layer at the surface of an electrode.
} 
In studying the action of any salt on an albumin solution, the real question to be answered is: What will be the result upon the solubility and state of the colloid of replacing the ion already in combination with the proteid by some other ion containing a different amount of potential energy? We have to know, therefore, before we can answer the question of the action of any salt on a colloid, what the ion is which is already in combination with it. This is a very important point, which is frequently overlooked in studying the action of salts.

To get a clear idea of what happens when a salt is added to an albumin solution, let us consider first, the condition of affairs in the sodium albumin solution in which the proteid exists as $\mathrm{Na}+$ albuminate. As the colloid stands in a saturated solution, it is in a condition of equilibrium. The sodium ion has separated a certain distance from the albumin ion. The distance it moves depends, no doubt, on several factors, but the most important will probably be its tendency to go into solution-i. e., its solution tension.* The positive ion of sodium repels a negative charge with a power equal to 2.54 volts. What the negative solution tension of the albumin ion is, unfortunately is unknown. The effect of the positive charge on the sodium will be, of course, to neutralize the negative charge on the albumin, but, owing to the fact that the sodium repels the negative charge and holds its positive charge so firmly, it is unable to neutralize it, and the colloid remains in solution. We have, in other words, an equilibrium between dissociated and undissociated sodium albuminate.

The question, then, to be solved is this: What effect will it have on the solubility of the colloid if we replace the sodium ion by another ion containing a different quantity of potential energy, i. e., having a different ionic potential? One of two results may be anticipated: either the dissociation will increase and the colloid go more completely into solution, or it will diminish and the colloid be more or less completely precipitated.

If we introduce an ion of higher potential than sodium, evidently the state of equilibrium can no longer be the same. Energy will pass from the positive ion to the albumin, and will in some degree hold or neutralize its negative charge. We may imagine that the new

*Many facts indicate that one of the most important factors in determining the ionization of salts is the ionic potential of its ions. For example, compare the ionization constants of the iodide, chloride, and bromide of mercury or silver; or compare the ionization of silver and sodium nitrates. 
ion no longer can move so far from the albumin, and in consequence more nearly neutralizes its charge. The result is that the surface of the colloidal particles will be reduced, the surface tension will be increased and the colloid will be less stable. In another way of putting it, the dissociation is somewhat reduced and consequently some of the colloid tends to precipitate. If, in fact, the ion used to supplant the sodium has a sufficiently high potential, it will practically not leave the colloid at all, the dissociation will be greatly reduced, the negative charges almost neutralized, and precipitation will occur. If the ionic potential of the introduced ion is still higher, it may oxidize the colloid; i. e., an actual exchange of charges will take place between the albumin and the ion.

If, however, an ion of lower potential is introduced in place of the sodium, the reverse of these processes will take place. Ionization will be increased, the negative charge will be freer, and the solubility of the colloid will be greater. This will be the case if potassium is substituted for the sodium, provided that potassium has a lower ionic potential than sodium, as is generally assumed, and that no other factors come into play.

It is, therefore, clear that the effect of any salt upon a saturated colloidal solution of albumin in which the albumin is electronegative will depend chiefly upon what ion is in combination with the colloid when the salt is introduced.

The quantitative differences in the effects of different salts must depend upon the differences in the ionic potentials of the ion in combination with the proteid and that substituted for it.

So far, we have considered only the rôle of the positive ion. That of the negative ion is also of importance, but somewhat more diffcult to picture to ourselves. We may, however, look at it in this way. The different negative ions introduced have different tendencies to deposit on the colloid, and give up their negative charges to it. This tendency is measured by the ionic potential of the ion. If the negative ion does deposit, it will tend to increase the negative charge on the colloid, and hence to dissolve it. The higher the ionic potential of the anion introduced, the greater must be its dissolving action on the colloid, since the greater will be its tendency to give its negative charge to the albumin. If the ionic potential of this ion is 
lower than the albumin, it will have an opposite or precipitating action, since then the colloid will tend to give up its charge to it.

These conclusions are confirmed by my results on sodium albuminate, and those of Osborne and Harris on edestin.

From these general considerations the conclusion may be drawn that the precipitating action of the salt on the colloid will be proportional to the difference between the ionic potential of the positive ion already combined with the colloid and that substituted for it; and that the dissolving action of the anion will be proportional to the difference in potential of the anion of the colloid and that we introduce; or

Precipitating action $=E_{c \text { salt }}-E_{c \text { colloid. }}$.

Dissolving action $=E_{a \text { salt }}-E_{a \text { colloid. }}$.

In this formula $E_{c \text { salt }}$ is the ionic potential of the cation of the salt introduced, and $E_{c}$ colloid that of the cation of the colloid. $E_{a}$ salt and $E_{a \text { colloid }}$ are the values for the anions.

Since these two actions are mutually antagonistic, the actual action of the salt will be equal to the difference between them, or

Actual action $=$ precipitating - dissolving action

$$
\begin{aligned}
& =E_{c \text { salt }}^{\mathrm{i}}-E_{c \text { colloid }}^{\mathrm{ii}}-E_{a \text { salt }}^{\mathrm{iii}}+E_{a \text { colloid }}^{\mathrm{iv}} \\
& =\left(E^{\mathrm{i}}-E^{\mathrm{iii}}\right)-\left(E^{\mathrm{ii}}-E^{\mathrm{iv}}\right) .
\end{aligned}
$$

If the result is positive, the salt should precipitate; if it is negative, it should dissolve the colloid. If it is zero, the salt should not affect the colloid except by mass action or by action on the water. In other words, the actual action of any salt on a colloid in solution will be proportional to the difference between the ionic potentials of the ions of the salt, minus the difference in ionic potentials of the ions of the colloid.

Let it be assumed that the logarithm of the dilution of the least precipitating concentration, or the logarithms of the dilution of solutions of equivalent dissolving power, are proportional to the actual action of the salt. ${ }^{\mathrm{x}}$ This gives the following equation:

$$
\log V=K\left[\left(E^{\mathrm{i}}-E^{\mathrm{iii}}\right)-\left(E^{\mathrm{ii}}-E^{\mathrm{iv}}\right)\right]+\text { const. }
$$

Comparing two salts with the sam a sign of action, i. e., dissolving or precipitating.

$$
\begin{aligned}
& \log V_{\mathrm{r}}=K\left[\left(E_{\mathrm{r}}^{\mathrm{i}}-E_{\mathrm{i}}^{\mathrm{iii}}\right)-\left(E^{\mathrm{ii}}-E^{\mathrm{iv}}\right)\right]+\text { const. } \\
& \log V_{2}=K\left[\left(E_{2}^{\mathrm{i}}-E_{2}^{\mathrm{iii}}\right)-\left(E^{\mathrm{ii}}-E^{\mathrm{iv}}\right)\right]+\text { const. } \\
& \log \frac{V_{\mathrm{I}}}{V_{2}}=K\left[\left(E_{\mathrm{I}}^{\mathrm{i}}-E_{\mathrm{r}}^{\mathrm{iii}}\right)-\left(E_{2}^{\mathrm{i}}-E_{2}^{\mathrm{iii}}\right)\right] .
\end{aligned}
$$

See Fig. I, p. 96. 
That is, the logarithm of the ratio between equivalent precipitating concentrations of two salts, divided by the difference between the differences of potentials of the ions of the two salts ought to give a constant.*

We thus have for the first time a formula for application to protoplasm which states clearly at the outset that the effect of any salt solution on the protoplasm will depend upon what ions are already in combination with the protoplasm. In other words, if we supplant mest of the ions in any cell by sodium, and then apply calcium chloride, the effect will be different from that obtained if calcium chloride is applied before the sodium chloride. Furthermore, the same salt will act differently on different cells, if only those cells have different ions in them. Both of these necessary conclusions of the theory have been established by observation. To make this perfectly clear, the difference in potential between the protoplasm and the salt solution which we started to measure is the difference in potential between the systems ionized colloid-ionized salt.

However, this formula cannot be applied directly as it stands to protoplasm as a whole, because it only applies to colloidal solutions in which the colloids are all of one sign. In protoplasm, however, it is certain that we have colloids of both signs and very probably amphoter colloids; i. e., colloids which are both positive and negative at different parts of the molecule. $\dagger$ We probably have, in other

* This formula may, I think, be substituted with advantage for that of the tension coefficient. It is in reality the numerator of the tension coefficient.

fA number of facts speak for the presence of such twin ions in colloidal albumin solutions and in protoplasm. For example, if egg albumin is dialyzed nearly free from salts, and then coagulated so as to form a weakly alkaline colloidal solution of albumin, and if this solution is then made acid, it is well known that the albumin becomes predominantly electropositive. That is shown by the colloid migrating slowly to the cathode in an electric field, and also by the combining power of the albumin, since it now combines readily with picric and other acids to form albumin picrate, tannate, and so on. Nevertheless, if the solution is not too acid, it will combine still with the metals in some measure. This is undoubtedly due to the composition and character of the albumin. The alkali albumin first obtained by heating is a salt. When the albumin has acid added to it, there is formed, in the first instance, the free acid of the albumin, which is not much dissociated. In addition, the acid is added to the amido-group, and in an excess of acid hydrolytic decomposition being greatly reduced, the dissociation takes place so as to make the albumin predominantly electropositive. However, the ionization of the acid is not entirely prevented, although it is greatly reduced, so that in some places we must have some hydrogen ions being formed leaving the albumin electronegative at certain places. It is probably this small percentage of hydrogen ions which can still be replaced by the metals. I found that, as a matter of fact, the heavy metals mercury and copper, although they would not in themselves cause a precipitate if the solution were sufficiently acid, yet they rendered the albumin far more easily precipitated than it was before. This is to be anticipated on our view that the colloidal particles are in some places negative and in other places positive. Not only does this appear to be the case for albumin, but in protoplasm there is also reason for believing that both ions of the salt are actually bound by the protoplasm, and especially in Fundulus eggs. It will be remembered that Du Bois Raymond long ago assuméd that such polarized particles might exist in protoplasm. 
words, ions like that in Fig. 2. As a matter of fact, if we try to apply this formula to the results on toxicity, a discrepancy between the response of protoplasm and colloidal albumin to salts is at once noticed. I have already called attention to this discrepancy. The discrepancy is this: While in the colloidal solutions the opposite action of the ions, dissolving and precipitating, is clearly apparent,

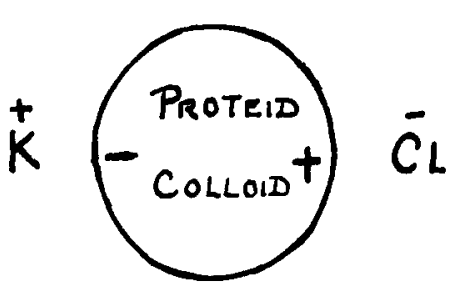

FIG. 2. Illustrating a colloidal twin ion dissociating at one place $\mathrm{K}$, and at another $\mathrm{Cl}$, leaving the colloid both negalive and positive at different places. and that opposite action is proportional to the ionic potentials of the anion and cation respectively, for protoplasm in general and for the ferment studied by McGuigan a different relationship is seen in that, instead of the positive ion counteracting by its energy content the negative ion, as it ought to do on the theory developed, a summation of effects is noticed. The iodides of the metals, instead of being less poisonous than the chlorides, as they should be, are more poisonous. The explanation of these facts is to be sought on the basis of the differently charged colloids present.

If these amphoter colloidal particles exist in protoplasm, or if we are dealing in protoplasm with a mixture of both negative and positive colloids, each ion will tend to precipitate. In the twin ions, if potassium is replaced by an ion of greater potential energy, the proteid will tend to be precipitated, since the negative part will be partially neutralized; and similarly if chlorine is replaced by an anion of greater potential. Both ions, therefore, will exert an action in the same direction, and there will be a summation of action in this case instead of a difference. The formula for toxicity would become:

$$
\begin{gathered}
\text { Total action }=\left(E_{\text {cation salt }}-E_{\text {cation colloid }}\right)+\left(E_{\text {anion salt }}-E_{\text {anion colloid }}\right) \\
=\left(E_{\text {cation salt }}+E_{\text {anion salt }}\right)-\left(E_{\text {cation colloid }}+E_{\text {anion colloid }}\right) ;
\end{gathered}
$$

or, writing $E_{c}^{\prime}$ and $E_{a}^{\prime}$ for the ionic potentials of the anion and cation of the salt introduced, and $E_{c}$ and $E_{a}$ for the ionic potentials of the ions bound to the colloid,

$$
\begin{aligned}
\log V^{\mathrm{i}} & =K\left[\left(E_{c}^{\mathrm{i}}+E_{a}^{\mathrm{i}}\right)-\left(E_{c}+E_{a}\right)\right]+C \\
\log V^{\mathrm{ii}} & =K\left[\left(E_{c}^{\mathrm{ii}}+E_{a}^{\mathrm{ii}}\right)-\left(E_{c}+E_{a}\right)\right]+C
\end{aligned}
$$




$$
\begin{aligned}
& \log \frac{V^{\mathrm{i}}}{V^{\mathrm{ii}}}=K\left(E_{c}^{\mathrm{i}}+E_{a}^{\mathrm{i}}-E_{c}^{\mathrm{ii}}-E_{a}^{\mathrm{ii}}\right) \\
& \frac{\mathrm{I}}{E_{c}^{\mathrm{i}}+E_{a}^{\mathrm{i}}-E_{c}^{\mathrm{ii}}-E_{a}^{\mathrm{ii}}} \log \frac{V^{\mathrm{i}}}{V^{\mathrm{ii}}}=K .
\end{aligned}
$$

That is, the logarithm of the ratios of the dilution of the minimum fatal doses of two salts, divided by the difference of the sums of the ionic potentials of the two salts, is a constant.

This formula is very similar to that derived by me empirically from a study of the dilutions of the minimum fatal doses of salts toward the eggs of Fundulus heteroclitus. The empirical formula was

$$
V_{a}=\frac{V_{o}}{2 \frac{E_{a}-E_{o}}{20.15+0.02 E_{a}}} .
$$

In this formula $E_{a}$ and $E_{o}$ were the decomposition tensions of the salts.

If we take instead of 2 the base of the Naperian logarithms 2.718 , and instead of $\frac{I}{0.15+0.02 E_{a}}$ we write $K$, this goes over into the form

$$
V_{a}=V_{o} \cdot 718^{-K\left(E_{a}-E_{o}\right)} \text {. }
$$

Taking natural logarithms

$$
\begin{aligned}
& \log V_{a}=\log V_{o}-K\left(E_{a}-E_{o}\right) \\
& \log \frac{V_{a}}{V_{o}}=-K\left(E_{a}-E_{o}\right) .
\end{aligned}
$$

This, in other words, is the same expression as that already derived, using the decomposition tension; i. e., the sum of the solution tensions of the ions, in place of the sum of the ionic potentials.

The formula may also be derived in another way. If $V$ is the dilution of the minimum fatal dose, and if we let $\mathrm{X}$ represent the difference between the sum of the ionic potentials of protoplasmic ions and salt ions, obviously from the form of the curve $\frac{d v}{d x}$ varies with its position on the curve, that is with $V$

$$
\begin{aligned}
\frac{d v}{d x} & =K V, \\
\therefore \log V & =K X+C=K\left(E_{c}^{\mathrm{i}}+E_{a}^{\mathrm{i}}-E_{c}-E_{a}\right)+C .
\end{aligned}
$$

An application of this formula to the results of McGuigan and myself give the following values for $K$. In each case it is assumed 
that the original ions in combination with the colloids are $K$ and $\mathrm{Cl} * *$

TABLE 5.

\begin{tabular}{|c|c|c|c|}
\hline Salts Compared & $\frac{\mathbf{I}}{E_{o}^{\prime}+E_{a}^{\prime}-E_{c}^{\prime \prime}-E_{a}^{\prime \prime}}$ & $\log \frac{V_{x}}{V_{2}}$ & $K$ \\
\hline 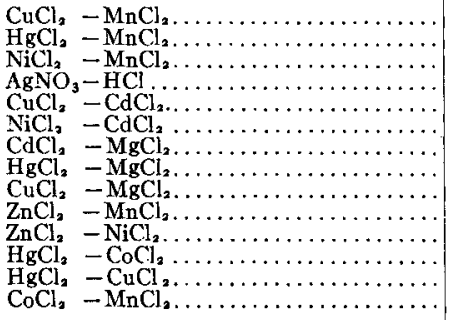 & 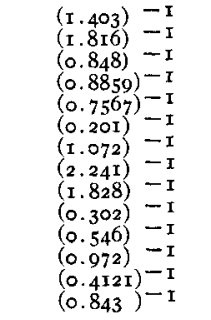 & $\begin{array}{l}\text { 3. } 1249 \\
3.6812 \\
2.163 \\
2.0044 \\
1.7655 \\
0.8035 \\
2.1553 \\
4.477 \\
3.9208 \\
1.0430 \\
1.1201 \\
2.4771 \\
0.5563 \\
1.2041\end{array}$ & $\begin{array}{l}2.23 \\
2.03 \\
2.55 \\
2.26 \\
2.33 \\
3.997 \\
2.010 \\
1.998 \\
2.145 \\
3.454 \\
2.051 \\
2.548 \\
1.35 \\
1.428\end{array}$ \\
\hline
\end{tabular}

Mean value of $K_{2.23}$

The values of $K$ (Table 5) are on the whole fairly constant for the great majority of the salts compared. The variations from the mean of 2.2 are due almost entirely to the fact that mercury is not so poisonous as it should be, and that cobalt is a good deal less toxic than the theory demands, while nickel is a little more toxic. The explanation of these variations is no doubt to be found in part in the dissociation. I have assumed throughout that the dissociation is complete. This has been done for the sake of simplicity. It is, however, certain that the dissociation of mercury chloride even in these dilutions is far from

* Some modification or explanation is necessary of the conclusion of a former paper that oppositely charged ions must have of necessity an opposite action. This is in one sense true. That is, the positive ion in combination with the proteid, if the latter is electronegative, must constantly be neutralizing the negative charge and producing undissociated albumin. It may be stated in this sense that the positive jon always tends to precipitate an electronegative albumin. It happens, however, that the power of neutralizing the charges of the colloid-that is, of reducing ionization-varies greatly in different cations, being greatest in those of high ionic potential, and least in those of low. If, therefore, we have, as we do have in a protoplasmic system, colloids in a state of equilibrium with ions already present, the particular direction of the change in state of that equilibrium produced by the substitution of new pasitive or neg. ative ions for those already present will depend on the relative potentials of the ions present and those introduced in their places. The actual effect observed, therefore, of replacing an ion of high potential with that of a low, will be the direct opposite of that produced by replacing the ion with an ion of still higher potential, and in this case there will appear to be an antitoxic or antagonistic action between two ions of the same character of charge. In an earlier discussion of this matter I neglected to take into account the great importance of the ions present in protoplasm. For example, suppose the ions in the protoplasmic system to be mainly sodium; and let us suppose that potassium has a lower potential than sodium, while calcium has a higher potential. If one substitute calcium for the sodium, the result will be to precipitate in part the electronegative colloids in the protoplasm. If, however, potassium be substituted for the sodium, the result will be to dissolve still further the colloids. In this case potassium and calcium will appear to exert an antagonistic action toward each other. If, however, the ions already in the protoplasm are of higher potential than calcium, then both potassium and calcium will produce the same kind of an action on the protoplasmic colloids. The results obtained by Loeb, Loeb and Giess, Miss Moore and myself on toxic and antitoxic action of salts thus have a very simple explanation. 
complete. If we assume it to be only 50 per cent, it would bring the mercury into its proper position. Similarly with cadmium, which is a trifle too low in its toxicity, this dissociation is certainly incomplete. As regards cobaltous chloride, which is noticeably below what it should be, I have no explanation to offer except to point out that it occupies the same exceptional position toward some other forms of protoplasm. Possibly its power of forming double compounds with ammonia and its derivatives may have something to do with its anomalous behavior.

The constancy of $K$ must be regarded, I think, with the exceptions just mentioned, as satisfactory, when it is remembered that the method of determining the minimum fatal dose-that is, by dilution-does not permit of very accurate figures.

$C$ evaluated from these figures was- 4:I II. (See Formula 4.)

TABLE 6.

Resutis on Fundulus EGgs.

\begin{tabular}{|c|c|c|c|}
\hline Salts Compared & $\left(E_{c}^{\prime}+\mathrm{E}_{a}^{\prime}-\mathrm{E}_{c}^{\prime \prime}-\mathrm{E}_{a}^{\prime \prime}\right)$ & $\log \frac{V_{I}}{V_{2}}$ & $K$ \\
\hline 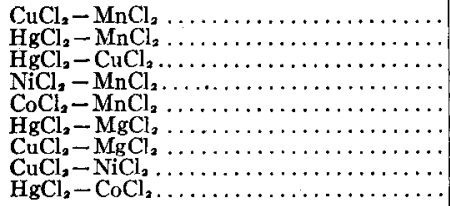 & $\begin{array}{l}(\mathbf{r} .403) \\
1.816 \\
0.412 \\
0.848 \\
0.843 \\
2.241 \\
1.828 \\
0.556 \\
0.972\end{array}$ & $\begin{array}{l}3.574 \\
4.097 \\
0.5229 \\
2.0969 \\
1.796 \\
4 \cdot 398 \\
3.875 \\
1.477 \\
2.301\end{array}$ & $\begin{array}{l}2.547 \\
2.260 \\
1.269 \\
2.473 \\
2.131 \\
1.964 \\
2.120 \\
2.655 \\
2.367\end{array}$ \\
\hline
\end{tabular}

Mean value $K=2.20$

TABLE 7

Comparison of $Z_{N}$ with all Other Metals.

\begin{tabular}{|c|c|c|c|}
\hline Salts Compared & $\left(E_{c}^{\prime}+E_{a}^{\prime}-E_{c}^{\prime \prime}-E_{a}^{\prime \prime}\right)$ & $\log \frac{V_{2}}{V_{2}}$ & $K$ \\
\hline 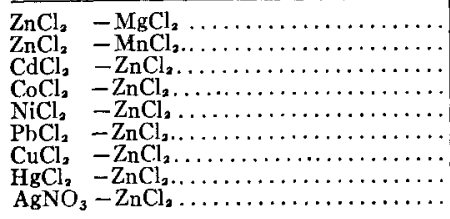 & $\begin{array}{l}0.726 \\
0.302 \\
0.345 \\
0.541 \\
0.546 \\
0.613 \\
1.102 \\
1.514 \\
1.597\end{array}$ & $\begin{array}{l}2.602 \\
2.301 \\
1.194 \\
-0.5051 \\
-0.2041 \\
0.795 \\
1.273 \\
1.7959 \\
2.097\end{array}$ & $\begin{array}{r}3.581 \\
7.610 \\
3.46 \mathrm{I} \\
-0.934 \\
-0.374 \\
\mathrm{I} .206 \\
\mathrm{I} .182 \\
\mathrm{I} .186 \\
1.314\end{array}$ \\
\hline
\end{tabular}

The results obtained upon Fundulus (Tables 6 and 7) do not give quite such constant values as those of McGuigan, and indeed with so complex a system this was not to be expected. However, the 
average value of $K$ in these results is almost exactly the same as that of McGuigan; i. e., about 2.2. The exceptions in these results are, with the expection of cadmium, the same as those recorded by McGuigan, cobalt being too little toxic and zinc too toxic. I have determined $K$ for zinc chloride in comparison with all other metal chlorides, expecting that, while the ratio would be too low for all other metals above it in the scale of ionic potentials, it would be too high for all metals below it, and these two errors should neutralize each other, provided the metals were about equally distributed above and below zinc. The result (Table 7) gave for the mean $K 2.03$, which is a litttle low, but fairly close to the mean 2.2 already obtained.

I have also determined (Table 8) the fatal dose just sufficient to stop swimming in two minutes in rapidly swimming cultures of Volvox globator. Four metals were investigated-i. e., silver, cadmium, manganese, and magnesium. $K$ was assumed to be 2.2 , the same as that for Fundulus and diastase, and the constant $C$ was calculated.

The result was as follows:

TABLE 8.

\begin{tabular}{|c|c|c|}
\hline Salt & $\log V$ & $C$ \\
\hline 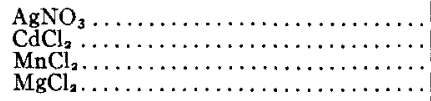 & $\begin{array}{l}5.477 \\
2.699 \\
1.699 \\
0.699\end{array}$ & $\begin{array}{l}-3.5 \\
-3.6 \\
-3.11 \\
-3.13\end{array}$ \\
\hline
\end{tabular}

The constant $C$ is thus found as constant, as could be expected from the methods used and the variability of the cultures.

Undoubtedly the most consistent and accurate results thus far obtained are those of McGuigan upon the minimum fatal dose of salts for the diastatic ferment. These results are plotted in Fig. 3. I have used only those results which were obtained with the metals $\mathrm{Mg}, \mathrm{Mn}$, $\mathrm{Zn}, \mathrm{Cd}, \mathrm{Co}, \mathrm{Ni}, \mathrm{H}, \mathrm{Cu}, \mathrm{Hg}$, and $\mathrm{Ag}$, for the reason that the solution tension, and hence the ionic potential, of all metals above magnesiumi. e., $\mathrm{Ca}, \mathrm{Sr}, \mathrm{Ba}, \mathrm{Na}, \mathrm{K}, \mathrm{Li}$, and $\mathrm{Cs}$ - are still so very uncertain as to make the comparison of ionic potential and fatal doses of little value. In Fig. 3 the line $A B$ represents the formula.

$$
\log V=C+K\left(E_{\text {cation salt }}-E_{\text {cation colloid }}\right)+\left(E_{\text {anion salt }}-E_{\text {anion colloid }}\right) \text {. }
$$


The ordinates represent the logarithms (common) of the dilution $(V)$ of the minimum fatal dose; the abscissæ represent the differences between the ionic potential of the cation of the colloid, which is assumed to be potassium at 2.9 volts and the ionic potential of the various

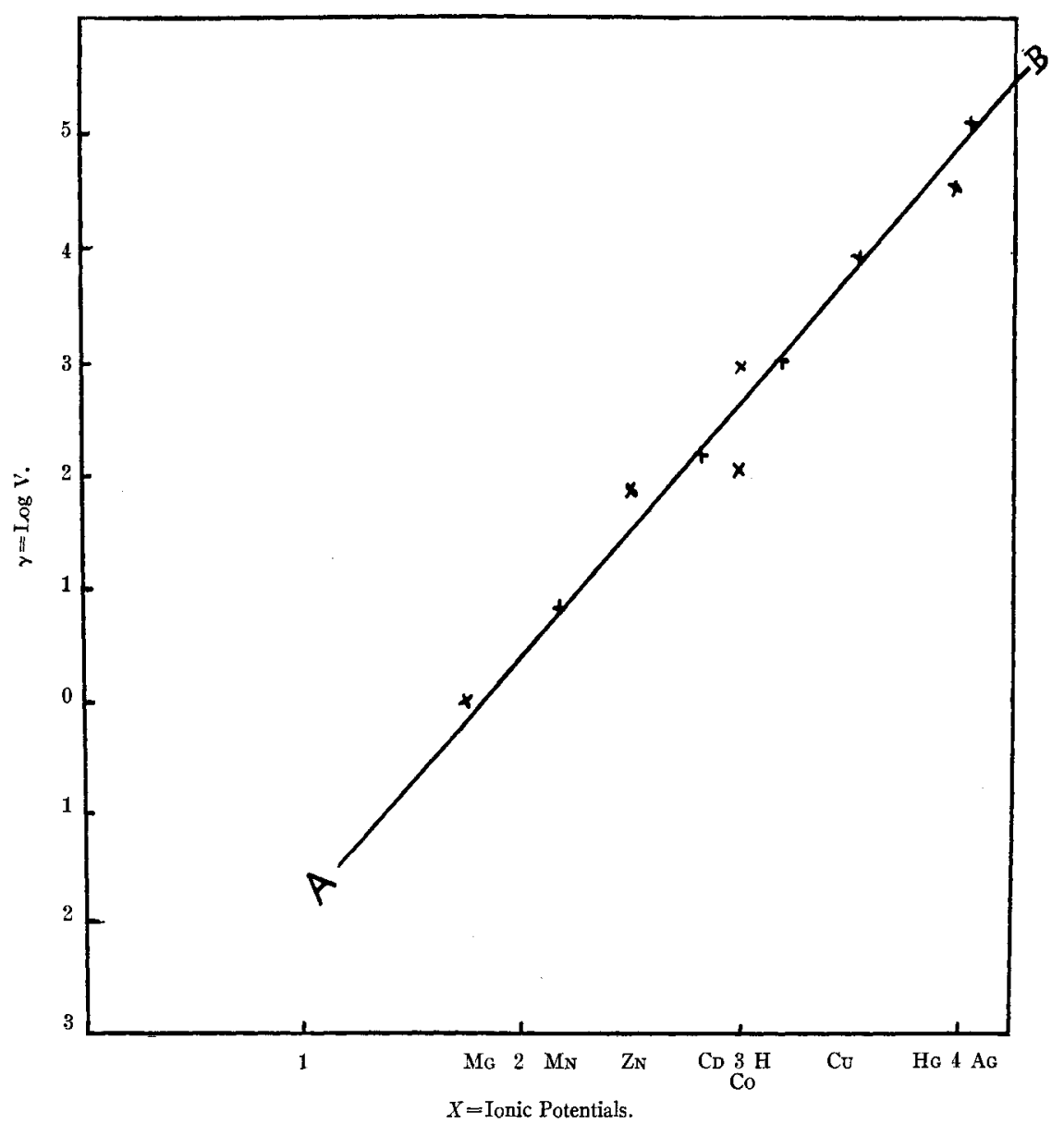

Fig. 3. Plat of results obtained with diastase. Ordinates are the logarithms of the dilution of the minimum fatal dose. Abscissa represent the difference between the ionic potentials of $\mathrm{K}$. $\mathrm{Cl}$ and potentials of ions of toxic salts.

metals. The line makes an angle with the $X$-axis, the tangent of which is 2.23, and it cuts the $Y$-axis at-4.I I (or $C$ ).

The remarkable closeness with which the various metals approximate to this line will be apparent. 
If now we turn to my results on Fundulus (Fig. 4), two things are at once clear from an inspection of Table 6 and Fig. 4. The first result is that the gradient or slope of the line which represents the relation between toxicity for Fundulus eggs and the ionic potential is

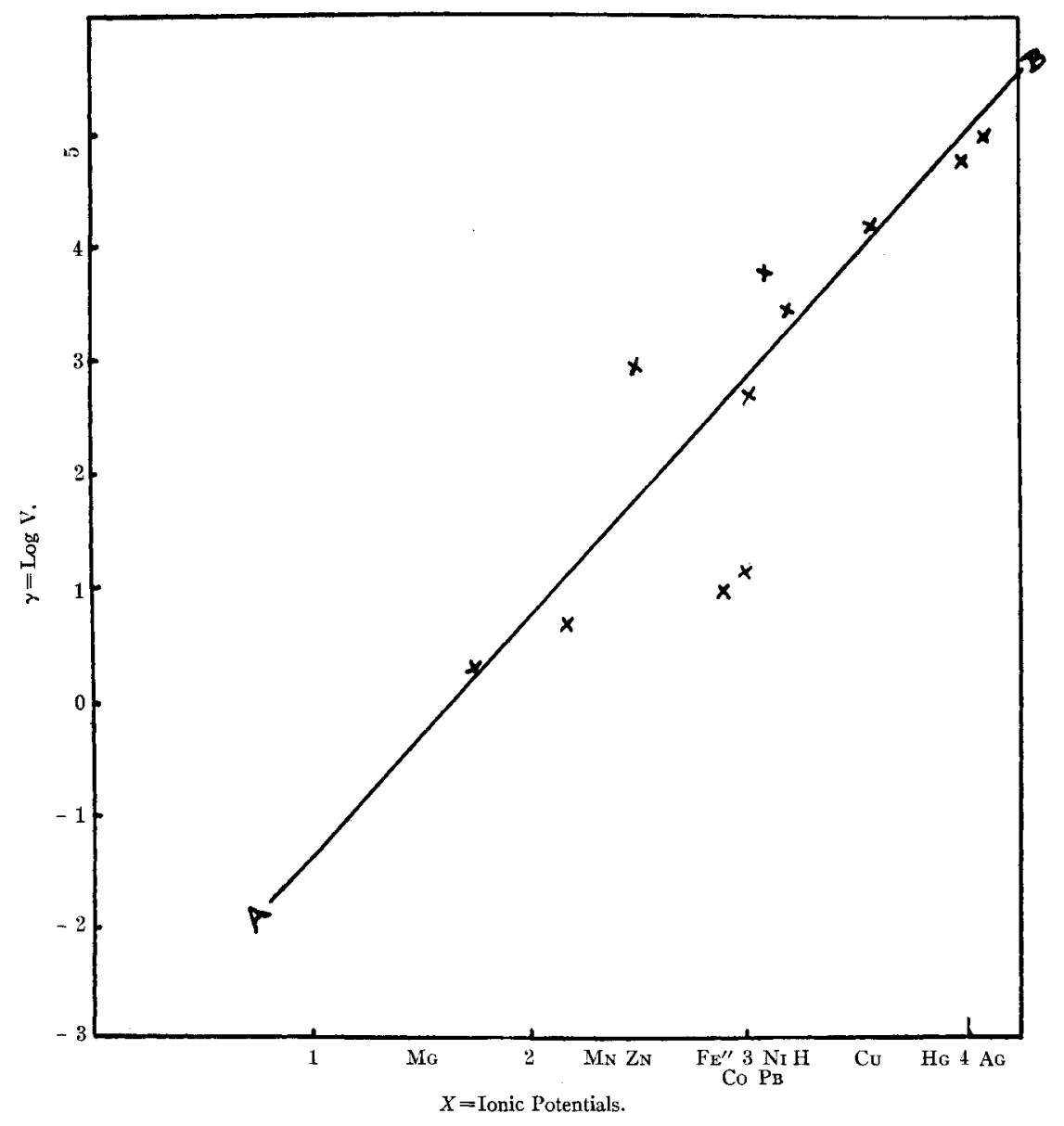

FIG. 4. Plot of results obtained with eggs of Fundulus heteroclitus. Ordinates and abscissæ as in 3.

exactly the same as that found for diastase. This must be regarded as confirmatory evidence of some value of the probable correctness of our attempt to work out a numerical relationship between toxicity and ionic potential. The second result which is very clear is that there is in the case of Fundulus greater variations than in 
the case of the ferment. This is, of course, to be expected since in the egg we are dealing with a vastly more complicated system than in the ferment. We have not only a variety of ferments and substances which might be differently affected by the salts, but the eggs are in addition separated from the water in which the salts are by membranes which are known to be variously permeable to different salts. The fact that the results show so good an agreement with the computed values is hence the more satisfactory. As regards the exceptions, it will be observed by comparing Figs. 3 and 4 that they are in general the same in each, only the deviations are greater for the egg. Thus zinc, which toward diastase was somewhat more poisonous than it should be, toward the eggs is very much more toxic. Cobalt, which is too little toxic toward diastase, shows the same relationship toward the eggs; the same is true of mercury. On the other hand, certain very interesting special exceptions occur. Thus cadmium, which toward diastase occupies almost exactly its theoretical position, is toward Fundulus heteroclitus eggs extremely toxic. It is, in fact, so toxic and so far out as to show that there is some specific and special reason for its aberrance. I have accordingly disregarded it. On the other hand, lead, which was for some special reason far out of place toward diastase, is here almost where it should be.

As regards the toxicity of the metals sodium, potassium, and lithium it will be noticed that they are relatively more toxic toward Fundulus than toward the diastase. The reason for this may possibly be that the strong solutions are in themselves harmful by their osmotic action on the cells.

I have also incorporated the results of a few observations made upon the rapidly swimming culture of Volvox globator (Fig. 5). I determined the concentration just sufficient to stop swimming within two minutes. The computation of the constant $a$, from the results gives a very satisfactory agreement.

e) Other results on toxicity.-The results of Caldwell on bromelin, the proteolytic ferment of the pineapple, I have been unable to bring to any satisfactory numerical agreement. But while Caldwell's results cannot be brought into quantitative relationship with McGuigan's and mine, the general trend of the results is plainly the same. The order of the toxicity of the metals is in nearly all cases as it should theoreti- 
cally be, so far as he has tried those of which the solution tension is known. The same exceptions are also apparent. Thus cobalt is not sufficiently toxic, and zinc is too toxic for the rule. Lead is about where it belongs, but in this case barium is the marked and peculiar

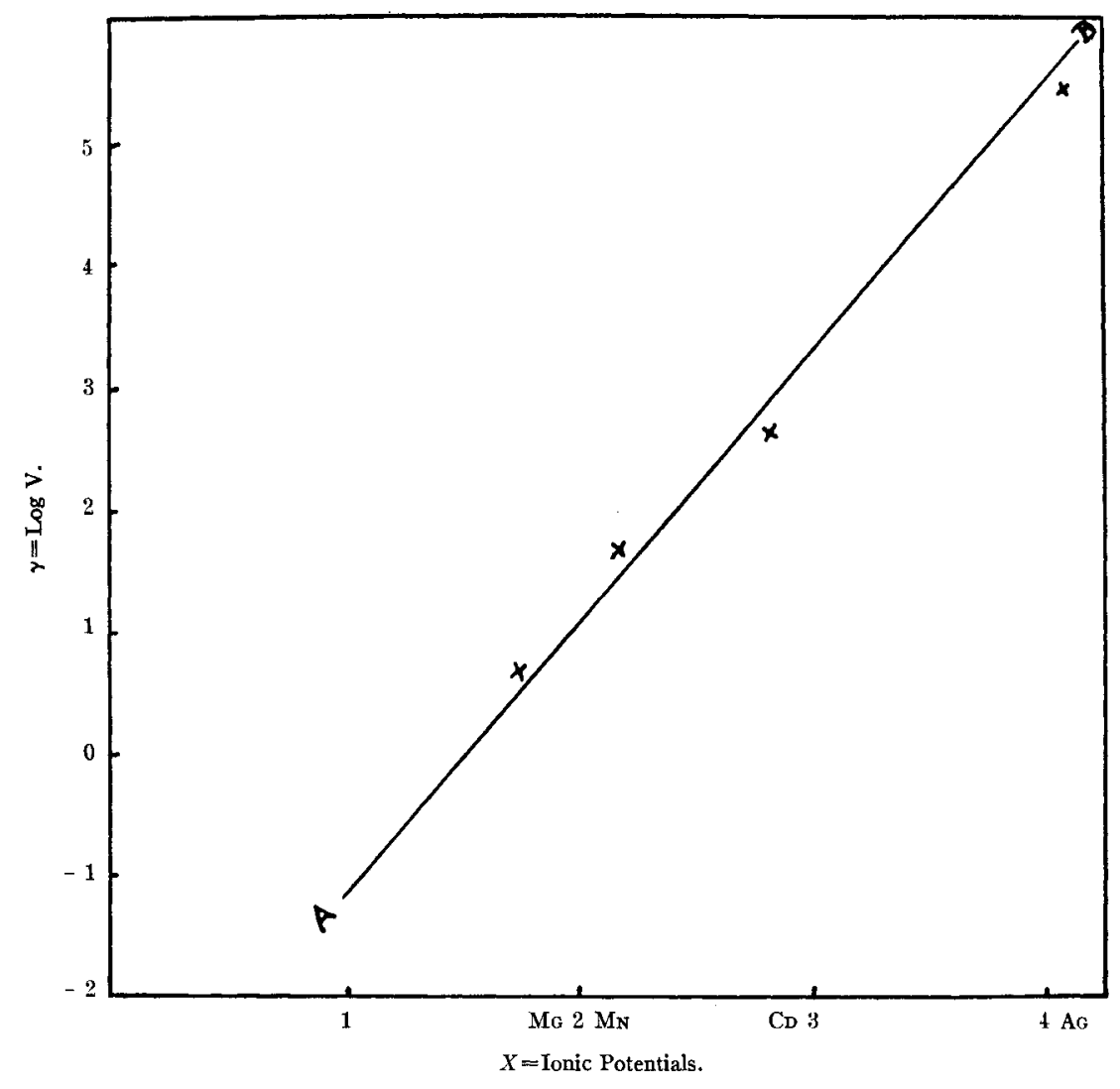

Fig. 5. Plot of results obtained with Volvox. Abscisse and ordinates as in Fig. 3.

exception, in place of the lead toward diastase, and cadmium toward the Fundulus egg.

The results of Heald (Table I) so far they have been obtained with the salts we are examining, show much the same order of effciency. Thus for Pisum sativum the order of toxicity is: $\mathrm{Ag}, \mathrm{Hg}$, $\mathrm{Cu}, \mathrm{Ni}, \mathrm{Co}$, and $\mathrm{H}$; while for Zea mais it is $\mathrm{Ag}, \mathrm{Cu}, \mathrm{Hg}, \mathrm{Ni}, \mathrm{Co}$, and $\mathrm{H}$. These results are not of a sufficiently definite character, based as they are on the growth of roots, to enable very accurate quan- 
titative comparisons. It will be noticed that nickel is more poisonous than cobalt for Pisum sativum, and far more poisonous than cobalt for Zea mais. Both of these roots appear less sensitive to acids than to the metals, the hydrogen ion being less toxic than nickel. With Lupinus, while the general order is the same as that observed elsewhere, cadmium is here more poisonous than copper-just the exception noted for Fundulus.

The results of Clark and Stevens upon mold spores are also for the purposes of quantitative comparisons unsatisfactory. These spores appear to be surrounded by such membranes, or to have so great a resistance, as to make the interpretation of results very doubtful, although there can be no doubt that the general trend of the results is the same as that already noted.

True and Kahlenberg's results (Table I) are more satisfactory, but, owing to the fact that these authors did not study many of the metals, and also did not pretend to fix the fatal point with accuracy, their results are not satisfactory for quantitative treatment. True's results upon the toxicity of the salts of the various acids are unfortunately unavailable for our purposes, owing to the uncertainty of the ionic potential of these anions.

f) The solubility of globulin in salt solutions.-In a previous paper $^{\mathrm{x}}$ I showed that the solubility of sodium albuminate (egg albumin in alkaline solution) in different salt solutions was determined by the tension-coefficient of the salt. By the tension-coefficient was meant the difference between the solution tensions of the ions divided by their sum. The numerator of this fraction should be the ionic potentials instead of the solution tensions. I showed that in an alkaline solution the solubility was greater in sodium iodide than in the bromide or chloride, and that when the ionic potential of the cation surpassed a certain figure the salts precipitated the albumin. Table $\mathrm{II}^{3}$ shows the relationship (qualitative) between the ionic potentials of salts and their power of dissolving or precipitating such albumin, both the unboiled and the boiled. It will be seen by an inspection of the table that the ionic potential arranges the salts in the order of their action on the albumin.

Osborne and Harris ${ }^{2}$ have estimated quantitatively the solvent

I Mathews, Amer. Jour. Physiol., I 905, I 4, p. 204.

a OSBORNE aND HaRRIs, ibid., I905, p. I5r.

3 Mathews, loc. cit., p. $21 \mathrm{x}$. 
power of many salts for the globulin of the hemp seed edestin. I append their results here to show how far they agrce with the theoretical deductions which were worked out on p. IO2. In Table $9 E_{c}-E_{a}$ represents the difference between the ionic potentials of the salts;

TABLE 9.

\begin{tabular}{|c|c|c|c|}
\hline Salt & $E_{c}-E_{\alpha}$ & $\begin{array}{l}\text { c.c. to Dissolve } \\
\text { I gr. }\end{array}$ & $K$ \\
\hline 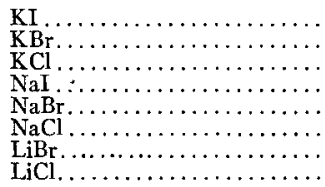 & $\begin{array}{l}-2.123 \\
-I .65 \\
-1.226 \\
-I .743 \\
-1.27 \\
-0.846 \\
-I .10 \\
-0.646\end{array}$ & $\begin{aligned} 5.7 \\
10 . \\
15.1 \\
5 \cdot 7 \\
9.3 \\
12.8 \\
12.1 \\
19.1\end{aligned}$ & $\begin{array}{l}.51 \\
.44\end{array}$ \\
\hline
\end{tabular}

the third column represents the number of c.c. of a normal solution of the salts which will just dissolve one gram of edestin. I have taken these figures from the chart given by Osborne and Harris. They are only approximate. The theory requires that the more negative the difference $E_{c}-E_{a}$, the smaller the amount of salt necessary to dissolve a given amount of the edestin. It will be seen that this relationship holds very well if we compare the iodides, chlorides, and bromides of sodium, lithium, and potassium respectively. Unfortunately, the great uncertainty of the solution tensions and ionic potentials of sodium, potassium, and lithium, prevent quantitative comparisons between the different metals. In the fourth column under $K, \mathrm{I}$ have computed the constant by the formula on p. 102, using instead of the logarithm of the dissolution the logarithm of the ratios of number of c.c. of the different solutions necessary to dissolve one gram. The figures are placed between the salts compared. The formula used was:

$$
\frac{\mathrm{I}}{\left(E_{c_{\mathrm{x}}}-E_{a_{1}}\right)-\left(E_{c_{2}}-E_{a_{3}}\right)} \log \frac{\mathrm{c} \cdot \mathrm{c}_{\mathrm{I}}}{\mathrm{c.cc_{2 }}}=K
$$

Osborne and Harris draw the conclusion that the solubility is independent of the nature of the base, but I think their figures speak for themselves. The differences between potassium, lithium, and sodium are small, to be sure, but nevertheless apparent. The importance of the base becomes obvious so soon as any other salts are examined in which the base has a higher ionic potential than 
these. Then it is seen that whether the salt dissolves the edestin or converts it into a curdy mass depends mainly on the base. The reason why so slight differences exist in the solvent power of the cations, sodium, potassium, lithium, barium, calcium, and magnesium, is shown by an examination of their ionic potentials, which are very low and probably about the same in each. The solvent power of manganese and ferrous chlorides is low.

$\mathrm{Cu}, \mathrm{Cd}, \mathrm{Cr}, \mathrm{Co}, \mathrm{Fe}^{\prime \prime \prime}, \mathrm{Pb}, \mathrm{Hg}, \mathrm{Cu}, \mathrm{Al}, \mathrm{Zn}$ chlorides and nitrates all fail to dissolve.

The solvent powers of the anions arrange themselves in descending order as follows: $\mathrm{CrO}_{4}, \mathrm{SO}_{3}, \mathrm{~S}_{4} \mathrm{O}_{3}, \mathrm{I}, \mathrm{Br}, \mathrm{Cl}, \mathrm{SO}_{4}$, which is almost certainly the descending order of the ionic potential of these ions. The fact that these bivalent ions of high ionic potential dissolve, instead of precipitating, the colloid, and that the valence of the anion is unimportant, is, in my opinion, good evidence that the edestin in such solutions is electronegative and not electropositive; for, as has been shown by Hardy and many others, the valence of the ion of the same sign as the colloid is immaterial, but toward a colloid of opposite sign it is very important.

The peculiarity of the dissolving action of the heavy metal acetates $^{x}$ also receives a possible explanation. In these solutions which dissociate acetic acid the edestin becomes electropositive. Consequently it is no longer precipitated by the positive ions, but receives energy from them, and is rendered more positive, and hence more soluble, than it was before. The cause of the failure of the chlorides to dissolve the edestin in acid solution would be that given by Osborne, that in such solutions, where there are many hydrogen ions, it is changed into edestan as an insoluble product.

I append here also a summary of the results of Pauli ${ }^{2}$ illustrating the same facts, showing the parallelism between the solvent or precipitating power of the anion upon albumin and its potential energy content. The parallelism is certainly unmistakable.

Order of precipitation . . . . . . . $\mathrm{SCN}>\mathrm{I}>\mathrm{Br}>\mathrm{NO}_{3}>\mathrm{Cl}>\mathrm{C}_{2} \mathrm{H}_{3} \mathrm{O}_{2}$ Ionic potential . . . . . . . . . . . . . . . . . . 83(?)-.79- . $.27-\mathrm{r} .694$

g) The phenomena of stimulation of cells.-I found that the salts ranged themselves very simply in the order of their energy content,

I OSBORNe AND HaRRIs, loc. cil., p. I65.

- PaUli, Hofmeister's Beiträge, r905, 6, p. 249. 
so far as their action, stimulation or depression, on the motor nerve was concerned. But it is clear from what has been said, that no such simple arrangement is to be anticipated in studying a complex system such as a cell undergoing rapid change. In such a system all we observe from the action of the salt is a definite result, which implies a certain change in the system. This result may be a stimulation, such as a muscle contraction, or nerve impulse. Evidently the same result may be brought about in several different ways: either by direct action of the salt on the particular part of the system which undergoes change; or, indirectly, by the salt altering another part of the system, so as to produce or check the result. It is conceivable that the same salt may have a double action: by one action tending to produce the direct change of the response; and indirectly by action on another part of the system having as a result the setting-up a process which will check its own direct action.

Something of this last process obtains, I believe, in protoplasm generally, so that strict adherence to the law of ionic potential action is not to be expected; but a general adherence is to be expected, and the facts show it exists.

An interesting example of this stimulating action is seen in the extrusion of polar globules in Chaetoplerus eggs. These eggs undergo the first processes of maturation before they are shed, but they do not extrude the polar globules until fertilized. The first polar spindle is formed and comes to rest in the equatorial platestage. Evidently in this egg there is not sufficient energy in the spindle to overcome the resistance offered by the surface tension or

TABLE Io.

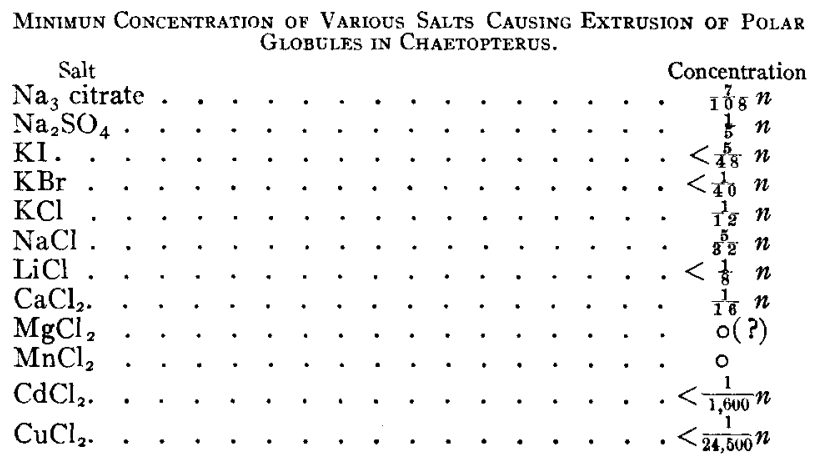


other factors, of the egg. Salts may cause extrusion either by increasing the energy in the egg, or by decreasing the surface tension.

Unfortunately the end-points were not determined accurately in many instances, but the figures (Table Io) suffice to show that the stimulation of this particular function was greatest in copper and cadmium, fell to nothing in manganese, was doubtful in magnesium, and then increased as salts having anions of higher ionic potential were used. In other words, if we begin with manganese or magnesium chlorides and pass to salts having a higher potential energy of either the anion or cation, this function is stimulated, and less of the salt must be used as the energy content increases.

GENERAL CONCLUSONS.

The general conclusions of this investigation are:

I. The action of salts upon the protoplasmic system is due chiefly to the ions of the salt.

2. The particular result obtained-toxic, stimulation, or depression excited by any salt solution-is caused, in part at least, by the substitution of the ions in the protoplasmic system, and in large measure in combination with the protoplasmic colloids, by the ions of the salt solution used.

3. This substitution causes a disturbance of the cquilibrium of the protoplasmic system, which, if sufficiently pronounced, leads to destruction.

4. The power of different ions to upset the ordinary state of the protoplasmic system depends on the difference between the potential energy content of the ion which is replaced, and that which is intro. duced. This difference in potential energy content is determined by the difference in the intensity factor of the potential energy of the ions-i. e., by differences in the ionic potentials.

5. It follows from 4 that the ions must arrange themselves in toxic power according to their available potential energy contents (ionic potentials). This was shown to be the case not only for toxic action, but also for stimulating and depressing action.

6. It was shown that a good numerical relation exists between the available potential energy of any salt and its minimum fatal dose, so that for simple systems the minimum fatal dose can be very 
closely calculated from the available potential energy of the salt, if certain constants are known.

7. A method was found for computing the ionic potential of various ions from the solution tensions.

8. In the case of Fundulus eggs, which were particularly investigated from this point of view, the order is also consonant with the theory, but the quantitative relationships, while fairly good, are not so uniform as in the case of diastase.

The character of the action of any given salt solution on protoplasm must of necessity depend upon the character of the ions, metal and metalloid, already in combination with the protoplasm. This results as a necessary consequence of the theory, and it explains the fact that toward different cells, and toward the same cell after exposure to different salt solutions, the same salt solution may exert a different action, being at times stimulating, at other times depressing.

It has been shown that the physiological action of any salt solution is a function of the available potential energy of its ions. The action of the organic drugs will, I think, also be found to depend, in part at least, on the available potential energy of the dissociated particles of the drug. 